\title{
EXTENUATING EFFECTS OF Terminalia catappa LEAVES AND Persea americana SEED EXTRACTS ON STREPTOZOTOCIN-INDUCED LIPIDS PERTURBATION AND PANCREATIC DAMAGE IN DIABETIC RATS
}

\author{
${ }^{1}$ Akinsanya, O. B. ${ }^{* 2}$ Ayodele, P. F., ${ }^{3}$ Onifade, O. F., \& ${ }^{4}$ Salimom, M. O. \\ 1,3,4 Department of Chemical and Food Sciences, College of Natural and Applied Sciences, Bells University of Technology, Ota, \\ Ogun State, Nigeria \\ ${ }^{* 2,3}$ Department of Biochemistry, College of Biosciences, Federal University of Agriculture, Abeokuta, Ogun State, Nigeria. \\ Corresponding Author Email: ayodele.peter@pg.funaab.edu.ng Phone: +2347036762316
}

\begin{abstract}
Diabetes mellitus develops either due to insufficient insulin secretion or lack of insulin resulting from damaged pancreas beta cells. Dyslipidaemia is an acute complication in diabetes mellitus. The aim of this study was to investigate the extenuating effects of $T$. cattapa leaves and $P$. americana seed aqueous extracts on streptozotocin-induced lipids profile perturbation and pancreatic damage in experimental rats. Thirty male albino rats were randomly divided into six groups $(n=5)$. Group 1: (negative control), group 2: 80 $\mathrm{mg} / \mathrm{kgbwt}$ streptozotocin (positive control), group 3: (80 mg/kgbwt streptozotocin $+200 \mathrm{mg} / \mathrm{kgbwt} \mathrm{T}$. catappa leave extract), group 4: (80 mg/kgbwt streptozotocin $+200 \mathrm{mg} / \mathrm{kgbwt}$ Persea americana seed extract), group 5: (80 mg/kgbwt streptozotocin $+200 \mathrm{mg} / \mathrm{kgbwt}$ extracts-mixture), group 6: (80 mg/kgbwt streptozotocin $+5 \mathrm{mg} / \mathrm{kgbwt}$ glibenclamide (standard drug). A single dose of streptozotocin was administered to the rats intraperitoneally; the extracts and glibenclamide were administered orally for 21 days, after which their pancreas was excised for histology. Thereafter, extracts of T. catappa leaves and P. americana seed on serum lipid levels imbalance in streptozotocin-induced diabetic rats were investigated. Histological studies showed a degenerative effect of the pancreatic islet cells of strotozotocin-induced groups. Results showed improvement in the regulation of lipid metabolism as well as the regeneration of the beta cells of pancreas on treatment with $T$. catappa leaves and $P$. americana seed. The extracts both equally exert significant antidyslipidemic effects in diabetic rats, in view of the extenuating effects of the extracts on pancreatic islet cells.
\end{abstract}

Keywords: Diabetes mellitus, Dyslipidaemia, Persia americana seed, Streptozotocin, Terminalia catappa leaves

LICENSE: This work by Open Journals Nigeria is licensed and published under the Creative Commons Attribution License 4.0 International License, which permits unrestricted use, distribution, and reproduction in any medium, provided this article is duly cited.

COPYRIGHT: The Author(s) completely retain the copyright of this published article.

OPEN ACCESS: The Author(s) approves that this article remains permanently online in the open access (OA) mode.

QA: This Article is published in line with "COPE (Committee on Publication Ethics) and PIE (Publication Integrity \& Ethics)". 


\section{INTRODUCTION}

Diabetes mellitus is regarded as a group of metabolic disorders classified into four broad categories: type 1, type 2, gestational diabetes, and "other specific types." This disorder has been a challenge to individual's health and lifestyle (Anthony et al., 2008). The usual indications of long-term or untreated diabetes may include weight loss, polyuria, polydipsia, and polyphagia (El-Wakf et al., 2011; Adeyi et al., 2015). Other visible signs and symptoms of diabetes may include headache, blurred vision, body weakness, slow healing of cuts, and itchy skin (Ziqi et al., 2015).

However, serious long-term complications include cardiovascular disease, stroke, chronic kidney disease, foot ulcers, and sever damage to the eyes. Type 1 diabetes mellitus (DM) is often managed with insulin injections. Type 2 DM may be treated with medications, with or without insulin. The consumption of lipid-lowering medications may bring about some adverse effects (Hosseini and Hosseinzadeh, 2015); some oral medications can cause low blood sugar (Jelodar et al., 2007; Yadav et al., 2008), and some must be carefully used during pregnancies.

Moreover, there is still a need to look for new and more tolerable drugs especially from natural sources such as plants that could be more effective on glycemic management alongside with insulin which has been shown to control diabetic complications effectively, and the fact that most of the modern pharmaceuticals used in diabetes management are expensive and not suitable for use during pregnancy (Luka et al., 2017).

The plant of Terminalia catappa is well-recognized in Ayurvedic medicine (Mininel et al., 2014). Its fresh leaves are used to prepare medicinal lotion to treat stomach discomfort, headache, scabies and leprosy among others (Mandloi et al., 2002). Earlier researchers have also reported the nociceptive potential of aqueous juice prepared by maceration from the tender leaves of T. cattapa to support its folklore use (Ratnasooriya and Dharmansiri, 2000). Also, a report on the ethno-pharmacological uses of the seeds of Persea americana in the treatment of hypercholesterolemia, high blood pressure, diabetes and inflammatory conditions among others, revealed some bioactivity and functional properties of the seeds (Imafidon and Amaechina, 2010).

Hence, this study aimed at finding the extenuating effects of the aqueous extracts of Terminalia catappa leaves and Persea americana seed on lipids profile perturbation in serum and pancreatic damage caused by streptozotocin administration in male albino rats.

\section{MATERIALS AND METHODS}

\section{COLLECTION OF PLANT MATERIALS AND PREPARATION OF EXTRACTS}

The tender leaves of Terminalia catappa (Indian almond fruit) and the Persea americana (avocado pear) seeds were collected from Bells University of Technology, Sango-ota, Ogun State, Nigeria. They were shade dried at room temperature. The dried leaves and seeds were subjected to coarse powder using a clean and dry grinder; the powder was later sieved respectively. Approximately $200 \mathrm{~g}$ of the powdered leaves and seeds, each was soaked into $2000 \mathrm{ml}$ distilled water for 48 hours. The extracts were filtered through muslin cloth, marc was discarded and filtrates were dried in a hot air oven at $45^{\circ} \mathrm{C}$ till a semi solid mass was produced. 


\section{EXPERIMENTAL ANIMALS}

Thirty (30) male albino rats, weighing approximately (150 -180) g were purchased from a local animal farm at Abeokuta, Ogun State, Nigeria. They were housed in plastic cages with net covered for ventilation and subjected to a standard environmental condition (12:12 hour light: dark cycle). They were fed with rat pellet feed ad libitum. Wood shavings were used as beddings for the animals; beddings were changed daily to avoid buildup of toxic ammonia levels. The rats were acclimatized for 2 weeks prior to exposure.

\section{ANIMAL GROUPING AND EXPOSURE}

The thirty rats were randomly divided into six groups $(n=5)$, including the negative and positive control groups. Each group contained five animals to avoid overcrowding and to allow easy accessibility and identification of the animals during the course of the research. All the groups, excluding the negative control group were administered a single dose (80 mg/kgbwt) of streptozotocin according to the method described by Dino et al. (2017), intraperitoneally. The blood glucose and body weight of the experimental rats were monitored for 1 week. Thereafter, the animals were treated orally with $200 \mathrm{mg} / \mathrm{kgbwt}$ aqueous extracts of the leaves of Terminalia catappa (Ravalya et al., 2013) and Persea americana seed (Okon et al., 2018), and $5 \mathrm{mg} / \mathrm{kgbwt}$ of glibenclamide (Daye et al., 2013) for 21 days as shown in Table 1.

Table 1: Experimental design

\section{GROUPS $(\mathbf{n}=\mathbf{5}) \quad$ TREATMENTS}

Group 1: Non-induced and untreated (negative control)

Group 2: Streptozotocin-induced $(80 \mathrm{mg} / \mathrm{kgbwt})$ and untreated

Group 3: Streptozotocin -induced $(80 \mathrm{mg} / \mathrm{kgbwt})+T$. catappa $(200 \mathrm{mg} / \mathrm{kgbwt})$

Group 4: Streptozotocin -induced $(80 \mathrm{mg} / \mathrm{kgbwt})+$ P. americana $(200 \mathrm{mg} / \mathrm{kgbwt})$

Group 5: Streptozotocin-induced $(80 \mathrm{mg} / \mathrm{kgbwt})+T$. catappa and $P$. americana $(200 \mathrm{mg} / \mathrm{kgbwt})$

Group 6: Streptozotocin -induced $(80 \mathrm{mg} / \mathrm{kgbwt})+$ glibenclamide $(5 \mathrm{mg} / \mathrm{kgbwt})$

The animals were considered diabetic with blood glucose $>200 \mathrm{mg} / \mathrm{dL}$.

\section{BIOCHEMICAL AND HISTOPATHOLOGY ANALYSIS}

At the end of the experiment, the animals were sacrificed by cervical dislocation. Blood samples were collected into fluoride oxalate bottles, allowed to stand for about 30 minutes, and centrifuged to obtain serum. Pancreas of the rats was harvested and histological preparation was made from the tissue for histological analysis. The serum was then analyzed for lipid profile. 


\section{DETERMINATION OF BIOCHEMICAL PARAMETERS}

Serum cholesterol, triacylglycerol and high-density lipoprotein (HDL) levels were determined using Randox kits according to manufacturer's instruction. Low density lipoprotein (LDL) was estimated using the method described by Gidez et al. (1982).

\section{HISTOPATHOLOGY PROCEDURE}

Histopathology is the microscopic study of diseased tissue. It is performed by examining a thin tissue section under light microscopes. The tissue (pancreas) was fixed with neutral formalin (10\%), embedded in paraffin, and then manually sectioned with a microtome to obtain 4-5 $\mu \mathrm{m}$ thick paraffin sections. Dewaxed sections were then stained with hematoxylin and Eosin blue ( $\mathrm{H}$ and $\mathrm{E}$ ). After staining, a very thin glass was placed over the tissue section to protect it and to enhance the optical evaluation of the tissue.

\section{STATISTICAL ANALYSIS}

Data were expressed as mean \pm standard error of mean (SEM) and were analyzed with SPSS software (version 17), using one-way analysis of variance (ANOVA) for multiple comparisons between groups, followed by Duncan's multiple tests. Differences between groups were considered significant at $\mathrm{p}<0.05$.

\section{RESULTS AND DISCUSSION}

Dyslipidemia is described as high levels of lipids (cholesterol, triacylglycerol, or both) carried by lipoproteins in the blood, which in-turn predisposes to cardiovascular diseases (Miller, 2009). Also, it may be regarded to when there is high cholesterol $>200 \mathrm{mg} / \mathrm{dL}$, high triacylglycerol $\geq 150 \mathrm{mg} / \mathrm{dL}$, low HDL-cholesterol $<40 \mathrm{mg} / \mathrm{dL}$, and high LDLcholesterol > $130 \mathrm{mg} / \mathrm{dL}$ (Fatema et al., 2016).

Table 2: Effects of $T$. catappa leaves and $P$. americana seed extracts on lipid profile in the serum of streptozotocininduced experimental rats $(\mathrm{mg} / \mathrm{dL})$

Groups Cholesterol (mg/dL) Triacylglycerol (mg/dL) HDL-chol (mg/dL) LDL-chol (mg/dL)

$\begin{array}{ccccc}1 & 1.80 \pm 0.15^{\mathrm{b}} & 0.46 \pm 0.12^{\mathrm{b}} & 1.27 \pm 0.03^{\mathrm{c}} & 0.7- \pm 0.10^{\mathrm{b}} \\ 2 & 2.40 \pm 0.12^{\mathrm{c}} & 1.10 \pm 0.20^{\mathrm{d}} & 0.60 \pm 0.21^{\mathrm{a}} & 1.30 \pm 0.40^{\mathrm{c}} \\ 3 & 1.93 \pm 0.18^{\mathrm{b}} & 0.30 \pm 0.15^{\mathrm{a}} & 1.17 \pm 0.03^{\mathrm{b}} & 0.43 \pm 0.17^{\mathrm{a}} \\ 4 & 1.30 \pm 0.10^{\mathrm{a}} & 0.73 \pm 0.07^{\mathrm{c}} & 1.20 \pm 0.10^{\mathrm{b}} & 0.73 \pm 0.03^{\mathrm{b}} \\ 5 & 1.37 \pm 0.27^{\mathrm{a}} & 0.53 \pm 0.03^{\mathrm{b}} & 1.10 \pm 0.10^{\mathrm{b}} & 0.77 \pm 0.03^{\mathrm{b}} \\ 6 & 1.97 \pm 0.03^{\mathrm{b}} & 0.63 \pm 0.13^{\mathrm{c}} & 0.90 \pm 0.20^{\mathrm{b}} & 0.47 \pm 0.09^{\mathrm{a}}\end{array}$

Data were expressed as mean \pm SEM $(n=5)$. Values having different alphabetic superscripts within the same column are significantly different $(\mathrm{p}<0.05)$. 


\section{HISTOPATHOLOGY}

Histology is a study of tissues which reflects the integrity and physiological architecture of the tissues.
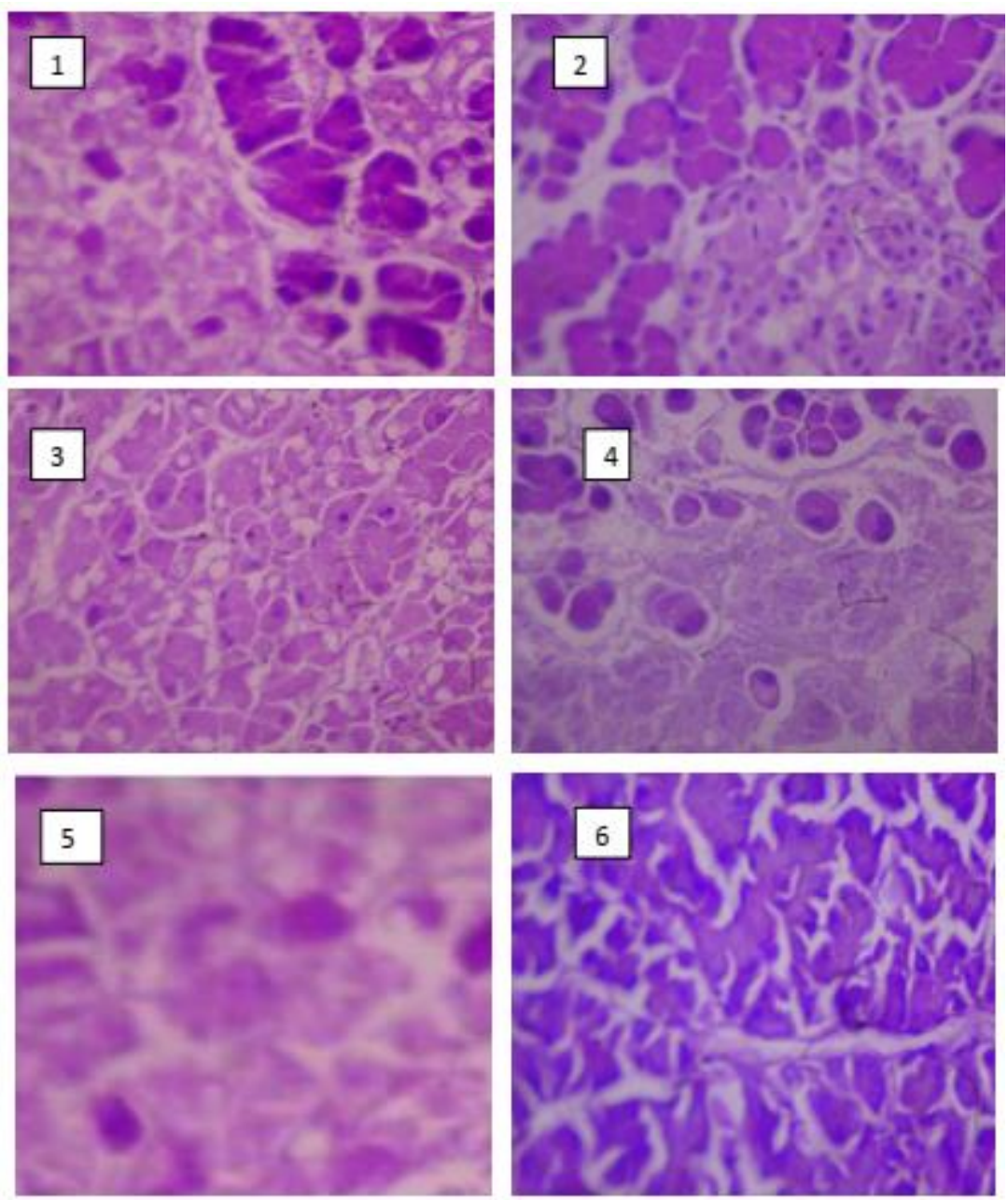

Plate 1: Effects of Terminalia catappa leaves and Persea americana seed extracts on the pancreas of experimental rats: Group 1 (negative control), group 2 (positive control), group 3 ( $80 \mathrm{mg} / \mathrm{kgbwt}$ streptozotocin $+200 \mathrm{mg} / \mathrm{kgbwt}$ T. catappa leaves extract), group $4(80 \mathrm{mg} / \mathrm{kgbwt}$ streptozotocin $+200 \mathrm{mg} / \mathrm{kgbwt} P$. americana seed extract), group 5 (80 mg/kgbwt streptozotocin +200 $\mathrm{mg} / \mathrm{kgbwt}$ extracts-mixture), group 6 ( $80 \mathrm{mg} / \mathrm{kgbwt}$ streptozotocin $+5 \mathrm{mg} / \mathrm{kgbwt}$ glibenclamide (standard drug)).

Magnification: $\times 400$

Table 2 showed effects of $T$. catappa leaves and P. americana seed aqueous extracts on lipid profile in the serum of streptozotocin-induced diabetes $(\mathrm{mg} / \mathrm{dL})$ in experimental rats. The cholesterol level in serum of the positive control (2) showed a significant $(\mathrm{p}<0.05)$ increase when compared to the negative control $(1)$. Treatment with extracts reversed the increase significantly $(\mathrm{p}<0.05)$ in cholesterol level of groups 4 and 5 , towards the level of the negative control (1). No significant ( $p>0.05$ ) difference was shown in groups 3 and 6 when compared to group 1.

There was a significant $(\mathrm{p}<0.05)$ increase in triacylglycerol level of positive control (2) when compared with the negative control (1). Extracts and glibenclamide treated groups reversed significantly $(\mathrm{p}<0.05)$ the level of 
triacylglycerol towards the level of negative control (1). Extracts-mixture treated group (5) showed no significant difference $(\mathrm{p}<0.05)$ compared to the negative control group (1). The significant $(\mathrm{p}<0.05)$ increase in triacylglycerol level observed is an indication that exposure to streptozotocin causes an up-regulation in lipid metabolism.

The positive control (2) showed a significant $(\mathrm{p}<0.05)$ decrease in HDL-chol level compared with the negative control (1). Extracts and glibenclamide treated groups showed a significant $(\mathrm{p}<0.05)$ increase in HDL level, towards the level of the negative control (1).

The positive control $(2)$ showed a significant $(\mathrm{p}<0.05)$ increase in LDL-chol level compared with the negative control (1). P. americana and extracts-mixture treated groups showed no significant ( $p>0.05)$ difference in LDLchol level when compared with the negative control (1). T. catappa and glibenclamie treated groups reversed significantly $(\mathrm{p}<0.05)$ the increase in LDL-chol level towards the level of the negative control $(1)$.

\section{DISCUSSION}

Diabetes is a pressing issue in the community. Its medication treatment is quite expensive; however, alternative herbal extracts play helping roles in the community (Palombo, 2005; Jachak and Saklani, 2007). Dyslipidaemia which is an acute complication in diabetes mellitus can be reversed by hypolipidemia activity, mainly by suppression of cholesterol luminal absorption and stimulate quick biliary excretion. There have been some reports that $T$. catappa leaf and P. americana seed extracts, and some of their pharmacologically active constituent possess lipid-lowering and antidyslipidemic effects alongside other nutritional and beneficial properties (Meyer and Terry, 2010; Ezejiofor et al., 2013a; Divya and Anand, 2018). This present study was carried out to examine the extenuating effects of Terminalia catappa (Indian almond) leave and Persea americana (avocado) seed aqueous extracts on serum lipid profile perturbation and pancreatic damage associated with streptozotocin-induced diabetes in male wistar rats.

Cholesterol (chol), triacylglycerol (TAG), low density lipoproteins (LDL) levels were elevated, and the highdensity lipoproteins (HDL) level in serum of the experimental rats decreased in streptozotocin administered group. The lipids investigated were present to attain a near normal level in serum of T.catappa leaves and Persea americana seed extracts treated rats and glibenclamide treated rats. The levels of cholesterol, TAG, HDL and LDL cholesterol were considerably $(\mathrm{p}<0.05)$ improved in the treated rats as compared to negative control rats. These biomarkers were set up to achieve a near normal level in serum of the extracts and glibenclamide treated rats. The increase in the LDL-chol level may be due to the streptozotocin administered to the experimental rats; which might be from the increased mobilization of free fatty acids from the peripheral fat depots.

The administration of aqueous extracts of $T$. catappa leaves and $P$. americana seed reduced the levels of cholesterol, TAG, LDL-chol, and increased the level of HDL-chol. The tissue extenuating or protective effects of the extracts observed by its efficacy to restore the already damaged tissue by might be due to the bioactive components which may be present in the plants (Okonta et al., 2007; Collins et al., 2018). Thus, our findings revealed that the aqueous extracts of $T$. catappa leaves and $P$. americana seed exhibited antidiabetic and its associated antihyperlipidemic activity in streptozotocin-induced diabetic rats. 
These findings support the traditional use of T. catappa leaves and Persea americana seed for controlling dyslipidemia in diabetes, as the hypoglycemic effects of the plants may be due to the presence of phenolic compounds and insulin-like substance in the plants Denni (2018), or regenerative effect of the plants on pancreatic tissue (Hosseini et al., 2015).

Plate 1 represents the histopathological study of pancreas of the experimental animals. The cellular integrity and architecture were undamaged in the negative control rats. Pancreatic sections stained with hematoxylin and eosin showed that streptozotocin caused severe necrotic changes of pancreatic islets, especially in the centre of islets. Nuclear changes, karyolysis, disappearance of nucleus and in some places, residue of destroyed cells were visible. Relative reduction of size and number of islets especially around the central vessel and severe reduction of beta cells were observed. Moreover, the histopathology results in the test rats showed a pancreatic islet cell degeneration, which was similar to N'guessan et al. (2009) and Antia et al. (2005) observations. The histology observation of the pancreas reflected that the negative control rats had intact pancreatic islets and exocrine cells but the streptozotocin-induced diabetic induced rats showed depleted islet cells and areas of cell necrosis. Pancreas of extracts treated rats showed evidence of signs of regeneration of the beta cells as revealed by histopathological studies. The improvement in cell and tissue integrity of the pancreas might be due to the regeneration of the beta cells.

\section{CONCLUSION}

The results of this study showed improvement in the regulation of lipid metabolism as well as the regeneration of the beta cells of pancreas on treatment with $T$. catappa leaves and $P$. americana seed. Their extracts both equally exerted significant antidyslipidemic effects in diabetic rats, in view of the extenuating effects of the extracts on pancreatic islet cells.

\section{CONFLICT OF INTEREST}

No any conflicts of interest, as declared by the authors.

\section{ACKNOWLEDGEMENT}

Appreciation to all participants who made this work a success but could not be part of the authors.

\section{REFERENCES}

Adeyi, A. O., Nnji, L. M., \& Idowu, B. A. (2015). Ameliorative potentials of medicinal plants on the pathophysiological conditions of diabetes mellitus: A review. Journal of Medicinal Plants Research, 9 (8): 262-288.

Anthony, A., Richard, K. B., Annika, D., Boris, D., \& Richard, D. F. (2008). Dietary carbohydrate restriction in type 2 diabetes mellitus and metabolic syndrome: time for a critical appraisal. Nutrition and Metabolism, 5 (1): $1-8$. 
Antia, B., Okokon, J., \& Okon, P. (2005). Hypoglycemic activity of aqueous leaf extract of Persea americana Mill. Indian Journal of Pharmacol ogy, 37: 325-326.

Collins, N. E., Ikechukwu, E. E., Moses, A., \& Peter, U. Achukwu (2018). Histopathological effect of aqueous extract of Persea americana seed on alloxan-induced diabetic rats. Journal of Pharmacology and Phytochemistry, 7 (1): 795-799.

Daye, C., Bin, L., \& Yunhui, L. (2013). Antihyperglycemic effect of Ginkgo biloba extract in streptozotocininduced diabetes in rats. Biomed Research International, 2013.

Denni, K. (2018). Extraction of total phenolic content of ketapang leaves (Terminalia catapa) using ultrasonic. World Chemical Engineering Journal, 2 (1): 6-11.

Dino, P., Robert, J. G., Sarah, S., Adrian, W., Michelle, A., \& Keske, B. (2017). A new method for targeted and sustained induction of type 2 diabetes in rodents. Scientific Reports, 7 (1): 1-10.

Divya, N., \& Anand, A.V. (2018). Antioxidant potentials of Terminalia catappa leaf extract in Streptozotocin induced diabetes in rats. Indian Journal of Animal Research, 52 (3): 358-362.

El-wakf, A., Tarek, M. A., Rizk, A. E., \& Wafaa, A. (2011). Role of hypertension and metabolic abnormalities in the development of diabetic nephropathy among Egyptian patients with type 2 diabetes. Nature science 7 (9): 220-228.

Ezejiofor, A. N., Okorie, A., \& Orisakwe, O. E. (2013a). Hypoglycaemic and tissue-protective effects of the aqueous extract of Persea americana seeds on alloxan-induced albino rats. Malaysian Journal of Medical Science, 20: 31-39.

Fatema, K.., Zwar, N. A., Milton, A., Ali, L., \& Rahman, B. 2016. Prevalence of risk factors for cardiovascular diseases in Bangladesh: a systematic review and meta-analysis. PloS one, 11 (8): e0160180.

Gidez, L. L., Miller, G. J., Burnstein, M., Slagle, S., \& Eder, H. A. (1982). Separation and quantitation of subclass of human plasma high density lipoproteins by a simple precipitation procedure. Journal of Lipids Research, 23: 1206-1223.

Hosseini, A., \& Hosseinzadeh , H. (2015). A review on the effects of Allium sativum (Garlic) in metabolic syndrome. Journal of Endocrinological Investigation, 38: 1147-1157.

Hosseini, A., Shafiee-Nick, R., \& Ghorban, A. (2015). Pancreatic beta cell protection/regeneration with phytotherapy. Journal of Pharmaceutical Sciences, 51 (1): 1-16.

Imafidon, K. E., \& Amaechina, F. C. (2010). Effects of aqueous seed extract of Persea americana mill. (avocado) on blood pressure and lipid profile in hypertensive rats. Advanced Biological Research, 4 (42): 112-116.

Jachak, S. M., \& Saklani, A. 2007. Challenges and opportunities in drug discovery from plants. Current Science, 92 (9): 1251-1257.

Jeloder, G., Mohsen, M., \& Shahram, S. (2007). Effect of walnut leaf, coriander and pomegranate on blood glucose and histopathology of pancreas of alloxan-induced diabetic rats. African Journal of Traditional, Complementary and Alternative Medicines (Afr. J. Trad. CAM), 4 (3): 299-305. 
Luka C. D., Istifanus G., Olatunde A., \& Eli Z. (2017). Effect of Aqueous Seed Extract of Terminalia catappa Linn on Some Biochemical Parameters in Alloxan-induced Diabetic Rats Journal of Applied Life Sciences International, 13(3): 1-8.

Mandloi, S., Mishra, R., Varma, R., Varughese, B. and Tripathi, J. (2002). A study on phytochemical and antifungal activity of leaf extracts of Terminalia cattapa International Journal of Pharmacy and Biological Sciences, 4: 1385-1393.

Meyer, M. D., \& Terry, L. A. (2010). Fatty acid and sugar composition of avocado, cv. Hass, in response to treatment with an ethylene scavenger or 1-methylcyclopropene to extend storage life. Food Chemistry, 121: 1203-1210.

Miller, M. (2009). Dyslipidemia and cardiovascular risk: the importance of early prevention. QJM: An International Journal of Medicine, 102 (9): 657-667.

Mininel, F. J., Leonardo Junior, C. S., Espanha, L. G., Resende, F. A., Varand, E. A., \& Leite, C. Q. (2014). Characterization and quantification of compounds in the hydroalcoholic extract of the leaves from Terminalia catappa Linn. (Combretaceae) and their mutagenic activity. Evidenced Based Complement and Alternative Medicine, 676-902.

N'guessan, K., Amoikon, K. E., \& Soro, D. (2009). Effect of aqueous extract of Persea americana seeds on the glycemia of diabetic rabbits. European Journal of Scientific Research, 26 (3): 376-385.

Okon, A. J., Etim, D. J., Daniel, A., Bobson, P. M. and Asuquo, A. E. (2018). Effect of ethanolic extracts of Persea americana seed and Zea mays silk on blood glucose levels, body and organ weights of alloxan-induced hyperglycemic albino wistar rats. Global Journal of Pure and Applied Sciences, 24 (2): 153-168.

Okonta, M., Okonta, L., \& Kasture, V. S. (2007). Blood glucose lowering activities of seed of Persea americana on alloxan-induced diabetic rats. Nigerian Journal of Natural Products and Medicine, 11: 26-28.

Palombo, E. A. (2005). Phytochemicals from traditional medicinal plants used in the treatment of diarrhoea: modes of actions and effects on intestinal function. Phytotherapy Research, 20: 717-724.

Ratnasooriya, W. D., \& Dharmansiri, M. G. (2000). Effects of Terminalia cattapa seeds on sexual behavior and fertility of male rats. Asian Journal of Andrology, 2: 213-219.

Ravala, P., Navaneetha, K., Subramanivam, S., \& Ram, P. (2013). Evaluation of synergistic activity of Hemidesmus indicus and Terminalia catappa on rheumatoid arthritis in rats. American Journal of Phytomedicine and Clinical Therapeutics, 1 (6): 514-519.

Yadev, J. P., Saini, S., Kalia, A. N., \& Dangi, A. S. (2008). Hypoglycemic activity of ethanolic extract of Salvadora oleoides in normal and alloxan - induced diabetes rats. Indian Journal of Pharmacology, 40 (1): 23-27.

Ziqi, T., Aimin, S., \& Jing, Z. (2015). Epidemiological perspectives of diabetes. Cell Biochemistry and Biophysics, 73 (1): 181-185. 